\title{
Familial Aggregation of Hypercholesterolemia in Pakistani Population
}

\section{Fauzia Imtiaz ${ }^{1}$ and Ahsan A. Vahidy ${ }^{2 *}$}

${ }^{1}$ Department of Biochemistry, Dow International Medical College, Dow University of Health Sciences, Pakistan

${ }^{2}$ Department of Genetics, University of Karachi, Pakistan

\begin{abstract}
Objectives: To estimate the familial aggregation of hypercholesterolemia among Pakistani population live in the metropolitan area Karachi.

Methods: The present study was conducted during the period of 2007 to 2009 on the sample population of Karachi Pakistan. In the present study, 478 family members (age ranges from 20 to 65 years), from ten-hypercholesterolemic probands (Cholesterol level $>300 \mathrm{mg} / \mathrm{dl}$ ) were studied and their serum cholesterol level was estimated to see the familial aggregation of the disease. The clinical examination was also performed to see the presence of tandinous xanthmata, xanthelesma, arcus cornea and polyarthritis.

Results: Parent-offspring correlation and heritability is calculated by using the statistical package for social sciences (SPSS) version 16.0. A significant positive correlation of cholesterol was found among parents and their offspring $(r=0.589, p=0.01, n=86)$. Relationship between father-son, father-daughter, mother-son and mother-daughter were highly significant with $b=0.794,0.41,0.766$ and 0.56 respectively. This study confirmed the familial aggregation of serum cholesterol level in Pakistani population and the heritability was calculated as $0.438(43.8 \%)$.
\end{abstract}

Conclusion: The heritability of hypercholesterolemia and their clinical presentation was studied in the families which confirmed its familial aggregation in Pakistani population.

\section{Introduction}

Familial hypercholesterolemia (FH) is one of the most common autosomal dominant disorder, of cholesterol metabolism in which qualitative and / or quantitative defect of the LDL receptor gene is observed. Elevated serum concentration of the total cholesterol (TC), and low density lipoprotein cholesterol (LDL-c) are major risk factors for coronary heart disease (CHD). Accordingly, much effort has been focused on the factors that determine serum TC and LDL-c concentrations. Study illustrates that the relationship of the FH genotype to the $\mathrm{FH}$ phenotype is not straightforward [1]. Genetic factors considered as a tool in determination of serum cholesterol levels [2]. Data obtained from different families have indicated that genetic factors accounted for about $50 \%$ of the inter-individual variation in serum TC concentration [3]. However, CHD particularly at a young age, largely influence by genetic variance. The influence of the genetic variance on serum lipids is of great interest. To our knowledge, estimation of heritability of $\mathrm{FH}$ with the risk of inheritance to their offspring has not been done specially in our Pakistani population. In this study, we therefore, estimate the magnitude of genetic influence on cholesterol level. The heritability index of serum cholesterol levels estimated by linear regression, the average of the offspring-serum cholesterol value on the mid-parent value, using weighted least-squares method [4]. We have previously reported that the cause of $\mathrm{FH}$ in Pakistani population is partly due to familial resemblance contributing due to the genes but other risk factors may also play a role in the progression of the $\mathrm{FH}$ disease in Pakistani population. Beside familial aggregation in the present study, we also studied and assessed the contri-bution of risk factors on the phenotypic expression of FH disease in a Pakistani population [5].

\section{Materials and Methods}

The probands with the family history of premature heart disease, high total cholesterol and low-density lipoprotein levels were included in the study. While individuals having hyperthyroidism, liver disorder and with any other confounding hypercholesterolemic factors were excluded. This is a cross-sectional study conducted during the year 2007-2009 and designed to recruit the population living in metropolitan area Karachi-Pakistan, screened for familial aggregation of hypercholesterolemia. Fifteen hundred and twenty three (1523), hypercholesterolemic individuals have taken part in the study; out of them ten were found to be familial hypercholesterolemia. These ten individuals and their families consists 478 members in which 86 pairs of parents with their offspring were taken part. The selection criterion of having familial hypercholesterolemia is; TC> $300 \mathrm{mg} / \mathrm{dl}$, LDL-c > $200 \mathrm{mg} / \mathrm{dl}$, and family history of premature coronary heart disease (CHD). The clinical examination of all family members of proband was done for the presence of tendenious xanthomata, xanthelesma, arcus cornea and polyarthritis.

For performing the laboratory tests $5 \mathrm{ml}$ blood was collected after overnight fasting (12-14 hrs). Serum total cholesterol levels measured using the CHOD-PAP method (Boehringer Mannheim, Germany). Lipid profile having Cholesterol, Triglyceride, LDL, and LDL-c measured following precipitation of apolipoprotein B-containing lipoproteins with phosphotungestic acid and magnesium ions (Boehringer Mannheim, Germany). Triglyceride concentrations measured by the GPO-DAOS method (Wako Co., Japan). All the lipid measurements were standardized and performed on Hitachi 901, automated analyzer (Hitachi, Japan). LDL concentrations calculated using the Friedewald formula [6]. The serum collected by centrifugation, immediately stored at $-20^{\circ} \mathrm{C}$ before it as transported in dry ice to the clinical laboratory for lipid measurements. The samples were then stored at $-70^{\circ} \mathrm{C}$ until analysis.

The statistical analysis was performed by Statistical Package for Social Sciences (SPSS) Version 16.0 (Chicago, USA). Linear

*Corresponding author: Dr. Fauzia Imtiaz, B-237, Block-N, North Nazimabad, Karachi-Pakistan, Cell: 0300-2116211, Tel: 9221-35478727; E-mail:f.imtiaz@duhs.edu.pk

Received December 20, 2011; Accepted May 04, 2012; Published May 08, 2012

Citation: Imtiaz F, Vahidy AA (2012) Familial Aggregation of Hypercholesterolemia in Pakistani Population. Hereditary Genet 1:109. doi:10.4172/2161-1041.1000109

Copyright: (c) 2012 Imtiaz F, et al. This is an open-access article distributed under the terms of the Creative Commons Attribution License, which permits unrestricted use, distribution, and reproduction in any medium, provided the original author and source are credited. 
regression analysis and Pearson correlation test was performed to see the relationship between the variables and estimation of heritability. Pedigree was made to observe the familial aggregation of disease by using the computer based software Cyrillic version 2.10 (Cherwell Scientific Publishing Ltd. Oxford, UK).

\section{Results}

Ten hypercholesterolemic probands, with cholesterol level $>300$ $\mathrm{mg} / \mathrm{dl}$ (normal range $140-240 \mathrm{mg} / \mathrm{dl}$ ), were selected with 478 family members, living in the metropolitan area Karachi-Pakistan. The study included 86 pairs of parents and their offspring. Heritability of the cholesterol was estimated by regression analysis, indicated that genetic factors accounted for $44.2 \%$ of the variance in cholesterol concentration $\mathrm{b}=0.442$ at $\mathrm{p}<0.01$.

The Pearson correlation coefficient modal applied to determine the significance level of offspring depends on their parent's cholesterol levels. Results were found to be positively correlated with $\mathrm{r}=0.589$ at $\mathrm{p}<$

\begin{tabular}{|l|c|c|}
\hline & Parent mean cholesterol & $\begin{array}{c}\text { Offspring mean choles- } \\
\text { terol }\end{array}$ \\
\hline Parent mean Cholesterol & 1.000 & $0.589^{* *}$ \\
\hline $\begin{array}{l}\text { Offspring average Cho- } \\
\text { lesterol }\end{array}$ & & 1.000 \\
\hline
\end{tabular}

${ }^{* *} p<0.01$ level.

Table 1: Pearson correlation between parent and offspring mean cholesterol.

\begin{tabular}{|l|c|c|c|}
\hline Relation & $\begin{array}{c}\text { Value of linear } \\
\text { regression (b) }\end{array}$ & $\mathbf{t}$ - value & Heritability (h) \\
\hline Parent-offspring & 0.442 & $5.897^{\star *}$ & 0.442 \\
\hline Mother-Son & 0.393 & $3.289^{\star *}$ & 0.750 \\
\hline Father-Son & 0.393 & $4.670^{\star *}$ & 0.750 \\
\hline Mother-Daughter & 0.290 & $5.036^{\star *}$ & 0.500 \\
\hline Father-Daughter & 0.207 & $3.327^{\star *}$ & 0.750 \\
\hline
\end{tabular}

** $p<0.01$ level

Table 2: Heritability between Parents and their offspring.
0.01 (Table 1). Pearson correlation analysis applied in order to evaluate the differences in transmitting the disease to their son and daughter. A positive significant differences found in the son and daughter cholesterol levels at $\mathrm{p}<0.01$ (Table 2). The heritability in different relations showed in (Table 2). According to our study, the son inherited more cholesterol concentration from their parent as compared to daughter. Mother-son, father-son are calculated as 0.750 and 0.750 , while mother-daughter and father-daughter correlation coefficients is found to be 0.50 and 0.75 respectively at $\mathrm{p}<0.01$ (Table 2 ). The study enables us to conclude that the risk of inheritance of high cholesterol from their parent was considerably higher in son as compare to daughter. The familial aggregation can also be seen in the pedigree of probands (Figure 1). On clinical examination of all the individuals the tendinous Xanthomata were observed in 358 members (75\%), Xanthelesma and arcus cornea were also present in 300 and 120 members i.e.,63\% and $25 \%$ respectively while the feature of polyarthritis was less common i.e., $2 \%$ (Table 3 ).

\section{Discussion}

The study is done on Pakistani population to estimates the familial aggregation of hypercholesterolemia in families with elevated levels of lipid and lipoprotein profile. The results intimate that these phenotypes strongly aggregated in families and characterized by significant have morel heritability estimates of $44.2 \%$. In addition, the lack of significance spouse correlation, combined with significant parent-offspring and sibling correlations, suggests that genetic factors are likely the major determinants of the familial aggregation. Life expectancy of patients with hypercholesterolemia is decreased due to the familial aggregation while, some untreated patients reach a normal life span and, therefore, additional risk factors and the type of mutation in the LDLR gene are likely to influence the clinical outcome [7]. Univariate and bivariate analysis of familial aggregations of cholesterol in 95 pedigrees showed that both in univariate as well as bivariate analysis, familial aggregation of serum cholesterol was strongly influenced by both shared gene and shared environmental factors [8]. Father-offspring and motheroffspring correlation were also found to be significant at $\mathrm{p}<0.01$ [9]. In comparison with the general population, the study found a similar 2 to

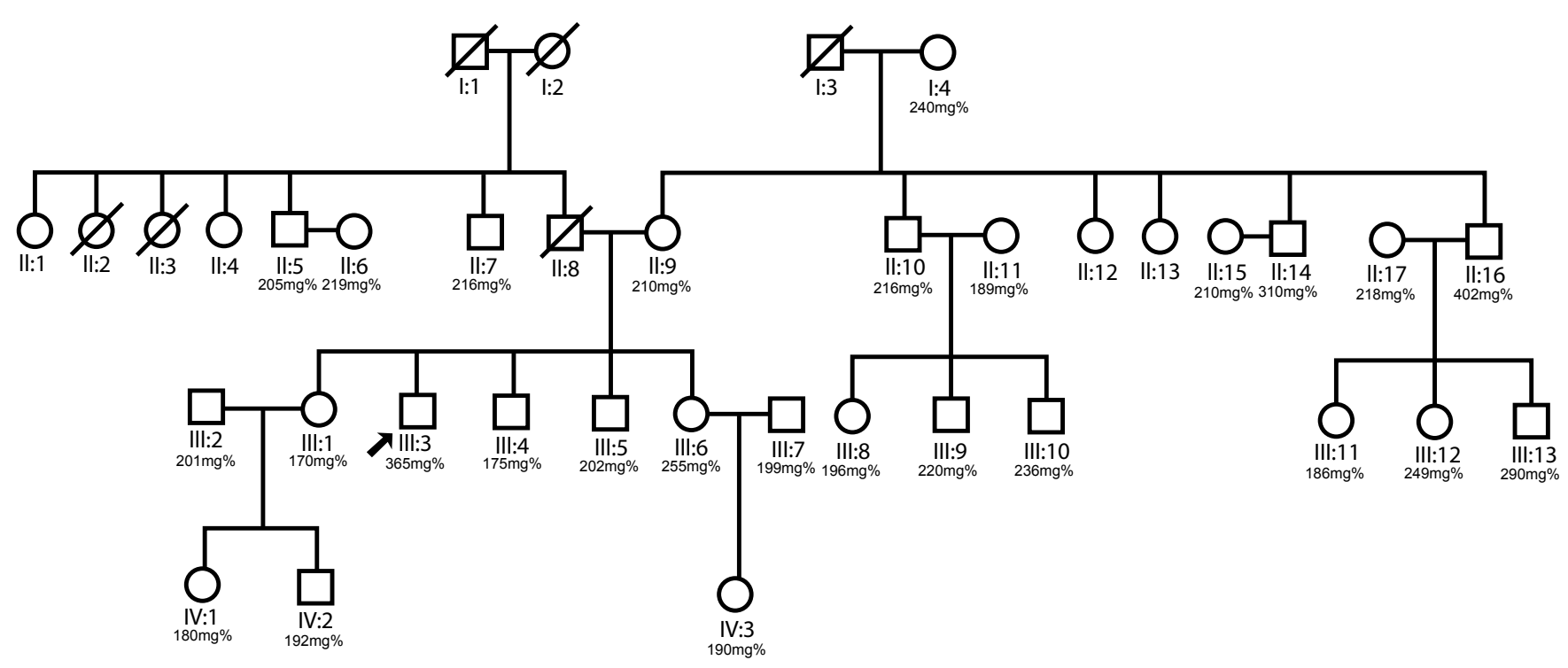

Figure 1: Pedigree of proband with TC $\geq 365 \mathrm{mg} / \mathrm{dl}$, LDL $\geq 200 \mathrm{mg} / \mathrm{dl}$. Diagnosed as Familial Hypercholesterolemia. 


\begin{tabular}{|l|c|c|c|}
\hline Observed Feature & Total No. of Cases & No. of observation & Percentage (\%) \\
\hline Tandinous Xanthomata & 478 & 358 & 75 \\
\hline Xanthelesma & 478 & 300 & 63 \\
\hline Arcus cornea & 478 & 120 & 25 \\
\hline Polyarthritis & 478 & 10 & 2 \\
\hline
\end{tabular}

Table 3: Clinical feature of participants.

3-fold higher coronary mortality both in patients with treated definite $\mathrm{FH}$ diagnosed on the basis of elevated cholesterol concentrations and this showed a dominant pattern of transmission of premature CHD [10]. Similar study was conducted on 139 White families and demonstrated that the familial aggregation of serum cholesterol was found to be highly correlated with the average parental value $r=0.43$ at $\mathrm{p}<0.01$ [11]. A heritage family study explained the influence of genetic factors in the adaptation to exercise training and its relationship with cardiovascular disease risk factor and the familial aggregation of lipids and lipoproteins among 86 Caucasian families [5].

This study is the continuation of our previous study which also showed the similar results with the heritability of $43.8 \%$ [12], showed that the pattern of familial correlations was significant between parent and their offspring, and again the heritability (h) of serum cholesterol was calculated as 0.442 (Table 2). These observations are similar to the results estimated on a Finnish population [13]. A significant positive familial correlation of cholesterol was found for the pairs of motheroffspring $(r=0.35)$, father-offspring $(r=0.29)$, mother-daughters $(r$ $=0.46)$, mother-sons $(r=0.27)$, and father-daughters $(r=0.29)$. The consistent cholesterol associations between mother and offspring indicated that the key role of the mother for the primary prevention of hypercholesterolemia. However in our study, when different relations were considered both the parents showed more significant role in transferring the trait to their son as compared to the daughter at $\mathrm{p}<0.01$ (Table 2). The family resemblance for lipids and lipoprotein on probands, selected from the Princeton School district, included 160 White, and 59 Black families and the estimated familial correlation by the method of maximum likelihood, father and child correlation was of larger magnitude in Whites as compare to Blacks for each lipid and lipoproteins and estimation of genetic heritability was larger in Whites than Blacks families [14]. Likewise the correlation ( $r$ ) in our study was observed as 0.589 at $\mathrm{p}<0.01$ (Table 1 ), which showed the positive correlation among parents and their offspring. Recently, the lipid profile in 115 Blacks and 99 Whites who participated in the heritage family study and the heritability ranges from $25 \%$ to $38 \%$ [15].

The criteria for the diagnosis are based on clinical examination also. It was also previously described in a study that tendon xanthoma, and xanthelesma was seen in FH patients similar finding were also seen in this study [16].

\section{Conclusion}

Heritability is the proportion of variance due to additive familial effects, including both genetic and non-genetic sources of variance. Although, the pattern of familial correlations in the Pakistani population, suggested that the familial aggregation equally contributed from the genes as well as environment for the disease progression of the hypercholesterolemia.

\section{References}

1. Damgaard D, Larsen ML, Nissen PH, Jensen JM, Jensen HK, et al. (2005) The relationship of molecular genetic to clinical diagnosis of familial hypercholesterolemia in Danish population. Atherosclerosis 180: 155-160.

2. Hegele RA (2001) Monogenic dyslipidemas: window on determinants of plasma lipoprotein metabolism. Am J Hum Genet 69: 1161-1177.
3. Wang J, Freeman DJ, Grundy SM, Levine DM, Guerra R, et al. (1998) Linkage between cholesterol 7alpha-hydroxlase and high plasma low-density lipoprotein cholesterol concentrations. J Clin Invest 101: 1283-1291.

4. Falconer DS 1989. Heritability. In: Introduction to quantitative genetics. Third Edi. English language book society. Longman, Hong Kong. Pp: 163-184.

5. Perusse L, Rice T, Despres JP, Bergeron J, Province MA, et al. (1997) Familia resemblance of plasma lipid lipases in the HERITAGE family study. Arterioscler Thromb Vasc Biol 17: 3263 -3269.

6. Imtiaz $F$ (2009) Estimation of heritability of familial hypercholesterolemia among 335 family members of five Hypercholesterolemia probands of Pakistan population. J Ayub Med Coll Abbottabad 21: 58-61

7. Friedewald WT, Levy RI, Fredrickson DS (1972) Estimation of the concentration of low density lipoprotein cholesterol in plasma, without use of the preparative ultracentrifuge. Clin Chem 18: 499-502.

8. Sijbrands EJ, Westendorp RG, Paola Lombardi M, Havekes LM, Frants RR et al. (2000) Additional risk factors influence excess mortality in heterozygous familial hypercholesterolaemia. Atherosclerosis 149: 421-425.

9. Boehnke M, Moll PP, Lange K, Weidman WH, Kottke BA (1986) Univariate and bivariate analyses of cholesterol and triglyceride levels in pedigrees. Am J Med Genet $23: 775-792$.

10. Morrison JA, Khouny P, Laskarzewski PM, Mellies MJ, Heinmeyer R, et al. (1982) Familial association of lipids and lipoprotein in families of hypercholesterolaemia probands. Arterioscler Thromb Vasc Biol 2: 151-159.

11. Neil HA, Huxley RR, Hawkins MM, Durrington PN, Betteridge DJ, et al. (2003) Comparison of the risk of fatal coronary heart disease in treated xanthomatous and non-xanthomatous heterozygous familial hyperchol-eterolaemia: a perspective registry study. Atherosclerosis 170: 73-78.

12. Sosenko JM, Breslow JL, Ellison RC, Miettinen OS (1980) Familial aggregation of total cholesterol, high density lipoprotein cholesterol and total triglyceride levels in plasma. Am J Epidemiol 112: 656-660.

13. Perusse L, Rice T, Despres JP, Bergeron J, Province MA, et al. (1997) Familia resemblance of plasma lipids, lipoproteins and postheparin lipoprotein and hepatic lipases in the HERITAGE Family Study. Arterioscler Thromb Vasc Bio 17: $3263-3269$.

14. Fuentes RM, Notkola IL, Shemeikka S, Tuomilehto J, Nissinen A (2000) Familial aggregation of serum total cholesterol: a population-based family study in eastern Finland. Prev Med 31: 603-607.

15. Rice T, Despres JP, Pérusse L, Hong Y, Province MA, et al. (2002) Familia aggregation of blood lipid response to exercise training in the Health, Risk factors, Exercise training and Genetics (HERITAGE) family study. Circulation 105: $1904-1908$

16. Goldstein JL, Hobbs HH, Brown MS (2001) Familial hypercholesterolemia In: Scriver CR, AL Beaudet, WS Sly, and D Vale (eds.) The metabolic and molecular bases of inherited disease, Vol. 120, New York, NY: McGraw-Hill Companies, Inc, pp. 2863-2914. 